\title{
The Benefits of an action reflective assessment using role-plays in teaching mediation
}

\section{Pauline Collins}

School of Law and Justice, University of Southern Queensland, Toowoomba, Australia.

\begin{abstract}
Introducing action reflection learning into a law course to instil life-long learner skills and enable students to adapt to a new style of lawyering is essential if $21^{\text {st }}$ Century lawyer needs are to be met. The paper describes the assessment, and the use of active reflective learning in a mediation course taught in an Australian law school. The benefits of such learning are described with specific attention to law teaching. Student reflections indicate the notable difference this teaching method had for their learning and development of a conflict resolution advocacy style.
\end{abstract}

Keywords: Action reflective assessment; role-plays; mediation; legal education. 


\section{Introduction}

Today's legal practitioners are adjusting to a different type of legal professional practice. Instead of 'warrior' lawyers relying on rights-based processes as an outcome achieved by the lawyer taking charge of the client's problems, clients are demanding a nuanced approach that requires a very different style of lawyering. This new professional is required to use communication not in a strong partisan advocate, winner takes all approach, but rather to advance their client's interests in a holistic and collaborative manner that sustains relationships and satisfies wider interests than purely monetary ones. Macfarlane (2008) has described it as a 'seismic change' from adversarial advocacy to conflict resolution advocacy (p.62). The dilemma for the law student is that much of their law school curriculum still focuses on adversarial advocacy. This can present a major block to adoption of a holistic conflict resolution communication when it comes to mediation training within a law school. Students have likened it to wearing two different hats. Adapting to the collaborative communication over a rights-based communication can be very difficult. It requires both, allowing greater ownership of the conflict resolution by the parties; and a recognition of the importance of needs and interest beyond mere rights.

Australian law students in particular are required to attain a Threshold of Learning Outcomes (TLO) based on six TLOs (Kift, et al 2010). TLO 6, Self-management, requires a reflective capability as a core skill (Marychurch, 2011). This is expressed as an ability for students to '(b) reflect on and assess their own capabilities and performance, and make use of feedback as appropriate, to support personal and professional development' (p.1) It has been fleshed out in the Good Practice Guide on how to teach and assess reflective practice skills (McNamara et al 2013). The reflective activities in the course support a self-management approach to learning by adjusting after feedback and reflection appreciating the development in capability and skills.

In a mediation law course delivered at both undergraduate and postgraduate levels in an Australian regional university, implementation of realistic role-play scenarios enables groups of three students to perform 'mock' mediations. Four mediations are conducted of around 90 minutes each, over a period of two days. The participants debrief immediately, both during and at the end of the role-play with each other and the coach. Debriefs are achieved by appropriate questioning eliciting the information the parties require to reflect on their learning. Each subsequent role-play builds on the reflective learning from the previous. This goes beyond a problem based learning that relies on adopting solutions centred on past experience, to instead follow action learning, requiring reflective practice and acting upon thinking concomitant with learning.

Action reflective learning allows assessors to set tasks that incorporate the elements of reflection, which include some form of real problem, or experience that is related to the 
participant's professional context, multiple participants, a range of potential responses, and opportunity for reflection both individually and in the group, and with an expert action learning coach (Marquardt 1999). The coach helps the participants by prompting, through appropriate questioning, active reflection, aiding in linking reflection to the theory, and guiding the improvement of skills. Freire's (1972) notions of praxis in which practice is purposefully integrated with the theory support this. Four schools of action learning have been identified, as 'tacit,' scientific,' 'experimental' and 'critical reflection' (Rimanoczy 2008). The latter is adopted in the law course discussed in this paper. Critical reflection involves addressing the context in which the problem arises by challenging assumptions, encouraging alternative approaches and inducing an empathetic appreciation of the consequences of actions as they affect outcomes and other parties. Action reflection provides a sustained and deeper learning that assists universities to produce $21^{\text {st }}$ Century graduates.

After outlining important aspects of action reflective learning this paper then links this to a description of the course and assessment. The benefits this learning and assessment approach brings to students is then discussed. Student reflections reported in this paper are drawn from a final reflection post to the study desk (from across 3 semesters) in which on average 250 students are taught in each semester. The following questions were posted on the study desk:

Describe some important things you have learnt in the course and if this has changed your thinking/approach to dispute settlement. What areas do you think you need to know more about and to develop in yourself?

Ethical consent was obtained to publish anonymized students’ responses.

\section{Action reflective learning}

Action reflection can occur in varied ways and this can create a lack of certainty as to what reflection assessment entails. The variety of models bringing theory and practice into an action reflective learning approach (Dewey, 1933, 1938; Schön 1983; Rogers 2001; Bond 2015), have been suggested as a success factor in action learning. The inbuilt flexibility allows for adult learning that ranges across cognitivist, behaviourist, humanist, constructivist, and social learning.

Dewey $(1933,1938)$ was seen as an early figure contributing to the concept of reflection in learning, noting that experience alone is not sufficient, but requires reflection on experience to actually learn from it. This supported action "....in a deliberate and intentional fashion...” in order for the individual to seek answers derives from a constructivist rather than behavioural view of learning (Dewey 1933, p.212; Bond, 2015, p.6). Friere (1972) refers to the need to adopt a critical thinking approach in which reflection can lead to problem solving by using complex thinking to overcome an otherwise narrow learning of information often 
not contextually situated (Bond 2015).

Schön (1983) was another early proponent in describing 'reflection-in-action' and 'reflection-on-action' (Ryan and Ryan 2012, p. 2). Schön's theory situated within everyday practice has been challenged as not providing the level of reflection required by Friere and others to initiate change and escape ‘oppressive' practice. This provokes a constructivist view of learning that contests the idea of an accumulated linear learning. Constructivists prefer to see knowledge as individually socially negotiated, leading to an absorption of new learning (Bond 2015, p. 5).

Drawing the theories on reflective practice together Rogers in 2001 described reflection as:

a cognitive and affective process or activity that (1) requires active engagement on the part of the individual; (2) is triggered by an unusual or perplexing situation or experience; (3) involves examining one's responses, beliefs, and premises in light of the situation at hand; and (4) results in integration of the new understanding of one's experience (p.41).

Each of these aspects are present for law students when learning a new communicative process through active application in a group mediation role-play. The group reflective exercise brings together people who have a shared knowledge, goals and attitudes that supports student learner self-assurance. Using the knowledge achieved by action reflection can result in a change of behaviour and ability to lead and adapt to change as the approach instils a confidence in students' ability to transition to professional practice (Sofo, et al, 2010).

Teaching reflective practice throughout the curriculum is important for students in order for the practice to become ubiquitous in their later professional capacity. However, this can be challenging for law students who are habituated to learning through a didactic approach based on following the Issues/Rules/Application/Conclusion (IRAC) concept (Graham 2015). This involves stating the issue in a problem scenario, identifying the related legal rules, then applying these to the given set of facts and drawing a conclusion. Summative assessment based on such an approach can fail to establish a lifelong learning approach that enables selfawareness of any gaps in knowledge and skills (Kift et al 2010). Reflection involves empowering students to take more responsibility for their learning. Without this, students risk becoming dependent on external rewards that fail to instil self-assessment of their capability to become a successful practitioner (Hammer et al 2012).

Further benefits from using a reflective learning approach include the potential to assist with law students afflicted with anxiety and depression (Skead and Rogers 2014; Collins 2016). Summative assessment can create a negative self-perception and is often experienced as separated from the learning process (Bond 2015, p.1). Reflective action learning assists 
graduates' flexibility and adaptability in responding to the context, developing their emotional intelligence and recognition of mental patterns, dialogue and personal interactions (Sofo et al 2010, p.213). This in turn may aid students' confidence and mental health (Field and Duffy 2012).

Providing an opportunity for reflection on action is important in law as it teaches the skills of self-regulation along-side core content knowledge. Reflexive questioning creates a metaawareness of how one's dialogue affects others including whether it can escalate or deescalate conflict. The skill is critical to survival of not only the individual but also organisations operating in the $21^{\text {st }}$ Century when changing environments, new technologies and flexibility are demanded. Creating a learning approach while still a student that inculcates values and ethical understanding based on one's actions enables good judgement when exercising professional responsibilities. This is important to those wishing to become resilient mediators.

\section{The Assessment}

Being a first year course (Law1122) and an early elective course in the Juris Doctor program (Law5122) the assessment gives the students a timely and beneficial understanding of the advantages of learning by doing and reflecting. This is taught to raise awareness of the student's metacognitive abilities. Essential aspects for action reflective learning include providing a challenging or new experience and a setting that encourages reflection (Rogers 2001, p.42). With these in mind the role-play mediations challenge students that have been put through a scaffolded structured learning, starting with relevant theory, then the mediation process, and finally combining the two in praxis. The predominant emphasis on rights based adversarial lawyering is directly challenged through this experience. It encourages students to question their world-view and assumptions. The following student reflections express the learning in moving to a conflict resolution advocacy, and experienced benefits not observed in an adversarial approach:

I began working in a law firm at the age of $16 \ldots$ It has been constantly stated to us that we defend our client's rights and protect these at all cost and this has been the only real approach that I have ever been exposed too.

Mediation is another way that the perceived view of lawyers can be improved, as they ... do not overly assert their authority but create a safe and relaxed environment.

... this course ... really allowed me to alter my thinking with regards to resolving disputes...Most importantly, I'd say I've come to learn 
that winning isn’t everything and that issues can actually be negotiated in a sense that allows both parties to 'win'.

Creating supporting assessment around the mediation role-play animates students' engagement in the process. The modelling of reflection by the coach and teaching team through appropriate questioning, demonstrating exemplars and guidance providing clear expectations and discussion helps the approach become embedded and integrated in a normalisation that nurtures reflective practice (Bond 2015). The coach facilitates learning by using guiding questions and interventions that focus attention on what is achieved well and what still needs to occur (Sofo et al 2010). Modelling a mediational conflict resolution approach, the coach empowers the students by creating a safe environment. This is supported by clear direction and criteria guiding the students towards desired learning outcomes.

There are a number of opportunities for reflection provided in Law1122/5122. One of the main assessment items is a reflective written assessment (worth 35\%) requiring the students to document and respond to one of four role-plays occurring over two-days in a face-to-face intensive. The diversity of feedback sources provided during and immediately following each role-play provides a critical richness in the learning experience. Students get to 'feel' the consequences of theirs and others actions. The intensive delivery of the active learning events enables an instant uptake of their reflection and response by putting it into practice in the next role-play. Beyond the individual and group reflection the whole class, comes together to share their learnings at the end of each role-play in an overarching debrief that adds to the diversity of voices to create thought-provoking insights.

Having learned the theory, process, and skills in scaffolded prior sessions the students are required to identify how this informed their experience by reflecting on the links between theory and practice in the written assessment. Each student experiences the mediations from the perspective of both mediator and a party as they rotate between the roles of party, and mediator. Contemporaneous notes from each role-play assist the further individual reflection in the subsequent written assignment. This requires students to select two scenarios, one as mediator and one as party from the mediation exercises. Students use these scenarios to link their experience with theory by critically commenting on which areas of the mediation process were successful or otherwise, and to conclude with an outline of key communication techniques utilised, evaluating their effectiveness with reference to theory.

Active learning reinforces and develops ability and skills in a short period giving a growing confidence, sense of achievement and self-esteem. This is witnessed by the expert coach as a dramatic improvement between the first and last role-play. Students describe the learning as an authentic 'real world' experience: 
... the discussion seemed 'real world' and I believe the skills and the way of thinking

... are very transferable to other situations as a lawyer.

... 'real world' application of the law is very different to the textbook approach.

Through constructing contextual and memorable experiences, student learning goes beyond the content to incorporate the self. Active involvement means the body memory is activated as more senses are engaged. Initial group reflection followed by written reflection provides the student with an opportunity for making the deep connections required for a lasting and profound awareness in order for their professional self to appear. A metacognitive awareness involves thinking about thinking in an active cognitive approach in which the self observes while also actively engaging in the role-play event. Memory is activated through the greater use of the senses and self-awareness (Bond 2015, p.3).

The individual written assessment provides a means to view the experience through a contemplative lens. In a holistic manner, the praxis experience relates current knowledge to past learning to create new learning. This can prompt conscious changes in behaviour based on a deeper reflexive understanding of when to use what skills. The following reflections indicate the meta-awareness of students' learning:

I was able to identify and develop the skills ... to communicate with clients of different cultures and backgrounds ...

I know that I have to work on being more impartial. I thought that this was something that I would be good at, although while studying this module I have found otherwise.

I've always been a 'listener' and now I understand something of why that can help others...

... by studying active listening and non verbal communication I gained a greater understanding of not just myself but others. Although I have to admit that I still need to practice my active listening...

Minor things such as interpreting people's body language is a trait I greatly undervalued and this course has demonstrated the usefulness of this.

A final reflection in a group post-action forum at the end of the course helps the students appreciate their most momentous learnings, and why they are significant. It moves beyond a description of an active learning exercise to the questioning of the students ideas and what motivates their world-view through self-critique. It demonstrates how the action reflective approach has assisted in overcoming Freire's concerns with breaking free ofthe oppressive: 
It's... hard to imagine what the practical process of doing law is when we're studying it. I have gained a greater understanding of the theory by putting it intopractice.

I learned so much about myself and what a challenge it is to step back and not get involved emotionally ...

Before I had always considered negotiations (involving lawyers) as the only real step to take before going to court, but now I understand that there are a lot of other options to try.

I have now gained the knowledge of why and how we do what we do to reach a positive outcome for our clients.

I found myself reading the types of personalities and saying... "I know someone like that at work" and thinking about the last disagreement you had with a friend and thinking ... perhaps if I had approached that a little differently things might not have gotten so out of hand.

\section{Conclusion}

Integrating a reflexive approach throughout a course both in a formative and summative manner develops the life-long learner and creates a meta-cognitive aware professional practitioner who is more likely to resist oppressive practice to become an informed flexible and adaptive lawyer. Including the student, instead of just the teacher in the assessment process intensifies the learning.

Key outcomes in the active reflective learning experience for a mediation course for law students include improved individual cognitive awareness and the ability to change behaviour, group reflection and feedback skills, reflexivity as a professional, learning that is remembered as it engages all senses, and lifelong active learning approaches.

\section{References}

Bond, John B. (2015). Reflective Assessment: Including Students in the Assessment Process in Forum on Public Policy, November 23.

Collins P. (2016). Australian Legal Education at a Cross Roads 58(1) Australian Universities' Review, 30.

Dewey, J. 1933. How we think: A restatement of the relation of reflective thinking to the educative process. New York: D. C. Heath.

Dewey, J. 1964. The need for a philosophy of education in John Dewey on education: Selected writings, ed. R. D. Archambault. Chicago: University of Chicago Press. 
Field, R. and J Duffy. 2012. Better to light a single candle than to curse the darkness: promoting law student well-being through a first year law subject Queensland Uni. of Technology Law and Justice Journal 12(1), 133-156.

Freire, P. 1972 Pedagogy of the Oppressed Harmondsworth, UK. Penguin.

Graham, L P. (2015). Why-RAC? Revisiting the Traditional Paradigm for Writing about Legal Analysis Kansas Law Review 63, 681-715.

Hammer, S; Chardon, T; Collins, P and C Hart (2012). Legal educators' perceptions of lifelong learning: conceptualisation and practice 31 International Journal of Lifelong Education 187-201.

Kift, S; Israel, M and R Field, (December 2010). Learning and Teaching Academic Standards Project: Bachelor of Laws Learning \& Teaching Academic Standards Statement, Australian Learning \& Teaching Council.

Macfarlane, J. (2008). The Evolution of the New Lawyer: How Lawyers Are Reshaping the Practice of Law Journal of Dispute Resolution, 61-81.

McNamara, J; Cockburn, T. and C Campbell. (2013). Good Practice Guide (Bachelor of Laws) Reflective Practice. Australian Learning and Teaching Council.

Marychurch, J. (2011). Good Practice Guide (Bachelor of Laws) Self-Management (Threshold Learning Outcome 6). http://lawteachnetwork.org/resources/gpg-selfmanagement.pdf.

Marquardt, M. (1999). Action learning in action. Palo Alto, CA: Davies-Black. Rimanoczy, I. (2007). Action Learning and Action Reflection Learning: Are They

Different? Industrial and Commercial Training 39(5), 246-56.

Rogers, R.R. 2001 Reflection in higher education: a concept analysis Innovative Higher Education 26(1), 37-57.

Ryan., M and M Ryan 2012. Theorising a model for teaching and assessing reflective learning in higher education. Higher Education Research and Development, 1-14

Skead, N, and S L Rogers. (2014). Stress, Anxiety and Depression in Law Students: How Student Behaviours Affect Student Wellbeing Monash University Law Review 40(2) 56487.

Schön, D. A. 1983. The reflective practitioner: how professionals think in action. New York Basic Books.

Sofo, F; Yeo, R K. and J Villafañe. (2010) Optimizing the Learning in Action Learning: Reflective Questions, Levels of Learning, and Coaching. Advances in Developing Human 12( ), 205-24. 